\title{
Environmental Influence on the Measurement of Exhaled Nitric Oxide Concentration in School Children: Special Reference to Methodology
}

\author{
Akira Murata ${ }^{1}$, Kouzui Kida ${ }^{1}$, Hideki Hasunuma², Hiroshi Kanegae', \\ Yasushi Ishimaru'2, Takashi Motegi ${ }^{1}$, Kouichi Yamada ${ }^{1}$, Hiroko Yoshioka ${ }^{1}$, \\ Kazuo Yamamoto ${ }^{1}$ and Shoji Kudoh ${ }^{1}$ \\ ${ }^{1}$ Department of Internal Medicine, Divisions of Pulmonary Medicine, Infectious Diseases, and Oncology, Nippon Medical School \\ ${ }^{2}$ The Center for Environmental Information Science
}

\begin{abstract}
Introduction: Measuring exhaled nitric oxide (eNO) is a noninvasive and useful method for evaluating the correlation between airway inflammation and air pollution. The method is being used in studies; however, the effects of polluted air on eNO values are poorly understood. If polluted air significantly affects eNO concentrations, then it would be hard to evaluate the concentration of eNO, particularly in epidemiological measurements to detect the effects of airway inflammation, such as that in bronchial asthma. Thus, we hypothesized that short-term exposure to air pollution affects eNO values.

Purpose: To study the effects of environmental nitrogen oxides on the measurement of eNO concentration.

Subjects and Methods: A total of 19 school children who lived on a large street with heavy traffic with random allocation were studied. Subjects with bronchial asthma were identified with a questionnaire. Suspended particulate matter. including particulate matter with an aerodynamic diameter $\leq 2.5 \mu \mathrm{m}\left(\mathrm{PM}_{2.5}\right)$, optical black carbon, nitric oxide (NO), nitric dioxide $\left(\mathrm{NO}_{2}\right)$, and nitrogen oxides $\left(\mathrm{NO}_{\mathrm{x}}\right)$, were measured at a fixed place along the street every hour for 11 consecutive days. The concentrations of $\mathrm{NO}$ and $\mathrm{NO}_{2}$ for each subject were measured by an individual 2-pyenyl-4,4,5,5-tetramethylimidazoline-3-oxide-1-oxyl sampler, and the concentration of eNO was measured with the off-line method.

Results: Of 19 subjects, 3 were found to have bronchial asthma. The level of each pollutant for 11 days peaked during the mornings $(6 \sim 9$ a.m.) and evenings $(6 \sim 9$ p.m.) due to traffic jams; average eNO values in healthy subjects and those with asthma were $27.1 \pm 9.7$ and $57.7 \pm 18.6 \mathrm{ppb}(\mathrm{p}=0.098)$, respectively. It was found that the eNO value remained high when the mean values of various pollutants remained high for 8 hours before the measurements. It was estimated that the mean eNO values increased by $1.08 \mathrm{ppb}$ (95\% CI: $0.72 \sim 1.45$ ) when the mean $\mathrm{NO}_{\mathrm{x}}$ value for the previous 8 hours reached approximately $10 \mathrm{ppb}$.

Conclusion: We conclude that short-term exposure to polluted air of at least 8 hours before measurement affects eNO values. Therefore, caution should be exercised when measuring eNO value in epidemiological studies.
\end{abstract}

(J Nippon Med Sch 2007; 74: 30-36)

Key words: Exhaled nitric oxide, nitrogen oxides, epidemiological study, short-term exposure, bronchial asthma

Correspondence to Akira Murata, MD, Department of Pulmonary Medicine, Infection and Oncology, Nippon Medical School, 8F JPR Ichigaya-Building, 4-7-15 Kudan-minami, Chiyoda-ku, Tokyo 102-0074, Japan

E-mail: a-murata@nms.ac.jp

Journal Website (http://www.nms.ac.jp/jnms/) 


\section{Introduction}

Exhaled nitric oxide (eNO) levels are high in airway inflammatory disorders, such as bronchial asthma $^{1-3}$. Measuring eNO is noninvasive and is an effective tool for evaluating airway inflammation in bronchial asthma, which is likely to be caused or exacerbated by air pollution ${ }^{4.5}$ and by intrinsic and extrinsic allergens. In this regard, the measurement method might be applied to epidemiological studies. One study by Franklin et al. ${ }^{6}$ found that prolonged exposure $(5 \sim 10$ weeks) to air pollution affected eNO values in infants. This result raises the possibility that exposure to ambient nitrogen oxide (NOx) affects eNO measurement, although the period of exposure required has not been determined. It might be crucial to study the short-term effects of exposure, such as that several hours before measurements of eNO for individual subjects, because the longer monitoring of $\mathrm{NOx}$ might be more costly, which may interfere with epidemiological studies to identify persons with asthma by measuring eNO. For this reason, we hypothesized that a short-term exposure to air pollution including NOx affects eNO values. The present study aimed to test this hypothesis methodologically.

\section{Subjects and Methods}

\section{Subjects}

School children were considered suitable subjects for evaluating the effects of short-term exposure to air pollution for this study, because they spend each day near measurement points, unlike adults, who move about a wider area. Therefore, for this preliminary study, 19 school children (13 boys and 6 girls), aged of 5 to 10 years were enrolled at random after obtaining informed consent from each of their parents.

A trunk road and a heavy traffic road were defined according to epidemiological standards ${ }^{7-11}$. In this study, we enrolled subjects residing close to a trunk road in Tokyo, Japan, with a traffic volume of more than 40,000 vehicles in a 12 -hour period during weekdays. Furthermore, the subjects were selected from among residents living within 20 to 350 meters from the corresponding street. Subjects with bronchial asthma were identified with the Japanese version of the American Thoracic Society-Division of Lung Disease (ATS-DLD) questionnaire ${ }^{12}$, as used in previous studies ${ }^{13}$.

\section{Measurement of eNO}

The eNO value of each subject was measured for 11 consecutive days from Nov. $2^{\text {nd }}$ to $12^{\text {th }}, 2004$, from 14 : 00 to 20 : 00 depending on the daily schedule of the individual, with the off-line $\operatorname{method}^{14-16}$, which has been shown to be equivalent to the on-line method ${ }^{17}$. Briefly, the subjects inhaled maximally and then exhaled air to the level of the maximal expiratory position with a constant pressure of $15 \mathrm{cmH}_{2} \mathrm{O}$ and with a speed corresponding as closely as possible to $50 \mathrm{ml} / \mathrm{sec}$, which was monitored on a screen. To avoid the collected air from being affected by the nasal cavity, upper airway, or outside air, the first $400 \mathrm{ml}$ of exhaled air was discarded; then, 200 to 400 $\mathrm{m} l$ of exhaled air was collected into a 1.5l Mylar sample bag. Within 2 hours after the air was sampled, each eNO value was measured using a chemiluminescent analyzer (Model NA-623N, Kimoto Electric Co., Ltd., Osaka, Japan). The complete measurement system employed in this study is illustrated in detail in Figure $\mathbf{1 .}$

\section{Measurement of Pollutants}

Changing levels of air pollutants at one designated place on the corresponding road were recorded every hour where the subjects resided; approximately 50 meters away from the main street $^{7.9}$, in accordance with the epidemiological study criterion set by the Ministry of the Enviroment ${ }^{18}$. Pollutants, including particulate matter with an aerodynamic diameter $\leq 2.5 \mu \mathrm{m} \quad\left(\mathrm{PM}_{2.5}\right)$, optical black carbon (OBC), nitric oxide (NO), and nitrogen oxides $\left(\mathrm{NO}_{\mathrm{x}}\right)$, were measured by a suspended particulate matter monitor and nitrogen oxides analyzer (Model SPM-613D, Kimoto Electric Co., Ltd.). 


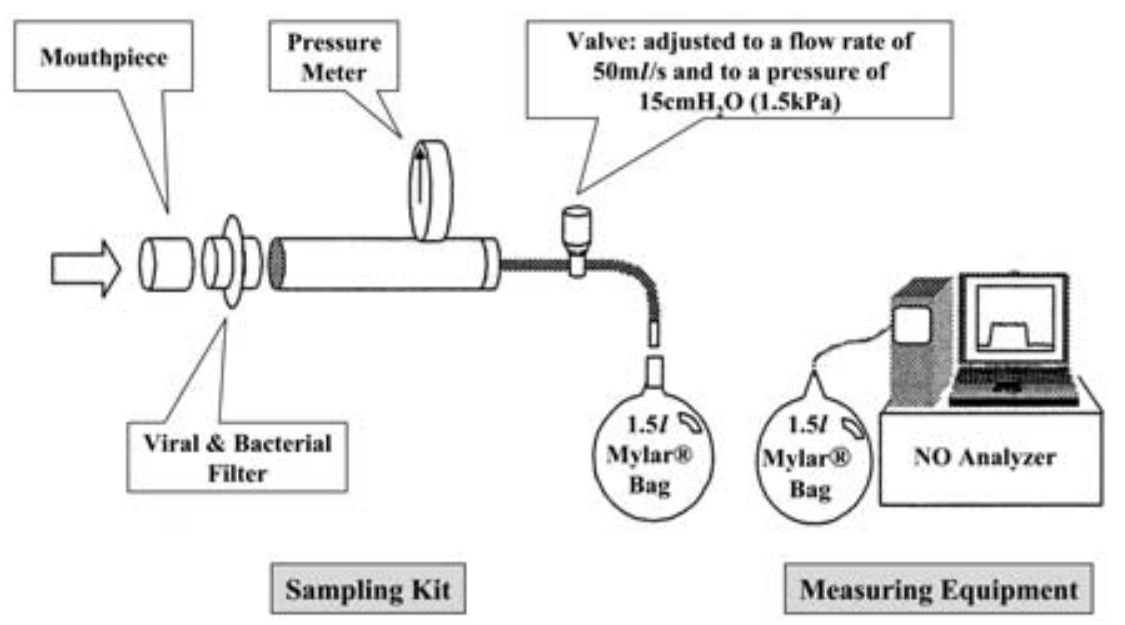

Fig. 1 Measuring equipment for eNO.

The complete measurement system for eNO using the off-line method $^{7}$ in this study is shown. The sampling kit (a mouthpiece, pressure meter, adjustable valve for expiratory air flow, and Mylar bag) (left) and measuring equipment (a chemiluminescent analyzer) (right).

\section{Individual Sampling of Air Pollutants}

A 2-pyenyl-4,4,5,5-tetramethylimidazoline-3-oxide-1oxyls (PTIO) sampler ${ }^{19}$, a small, portable measuring instrument, was attached to each subject's clothes. The sampler was used to collect air-samples for evaluating individual effects by measuring the total amounts of $\mathrm{NO}$ and $\mathrm{NO}_{2}$ every 24 hours for 11 consecutive days from November 2 to 12, 2004.

\section{Statistical Analysis}

The data were analyzed with standard statistical techniques using SPSS for Windows (version 8.0; SPSS, Inc. Chicago, IL, USA). Data are expressed as the mean \pm standard deviation of the mean (S.D.), and differences with a P-value less than 0.05 were considered significant.

Models were created to examine the relative roles of various exposure windows on eNO concentrations and the relative roles of individual pollutants, which were highly correlated. Separate models were created for individual hourly lag models and for moving average models to reflect cumulative exposures to remove irregular variance from the time series. All modeling was performed with the General Linear Model procedure in SAS (SAS Institute, 1997). To test whether there was heterogeneity in the response to $\mathrm{NO}, \mathrm{PM}_{2.5}, \mathrm{NOx}$, and $\mathrm{OBC}$, we also fitted mixed models allowing a random slope. We then tested whether the variability in slopes was significant ${ }^{20}$.

\section{Results}

\section{Subject Characteristics}

The mean age of the subjects was $7.8 \pm 1.5$ years. Of the 19 subjects, 3 were identified as having bronchial asthma by the ATS-DLD questionnaire.

\section{Daily Changes of Each Pollutant}

Mean values per hour of each pollutant including $\mathrm{NO}, \mathrm{NOx}, \mathrm{PM}_{2.5}$, and $\mathrm{OBC}$ for 11 consecutive days reached a maximum in the morning $(6 \sim 9$ a.m. $)$ followed by the evening (6 9 p.m.) (Fig. 2). The values of $\mathrm{NO}_{\mathrm{x}}, \mathrm{PM}_{2.5}$, and $\mathrm{OBC}$ varied over a range of 20 to $350 \mathrm{ppb}, 10$ to $120 \mu \mathrm{g} / \mathrm{m}^{3}$, and 1 to $20 \mu \mathrm{g} / \mathrm{m}^{3}$, respectively. The daily mean values of $\mathrm{NO}_{\mathrm{x}}, \mathrm{PM}_{2.5}$, and $\mathrm{OBC}$ during the study period showed a wide variation: $114.3 \pm 71.0 \mathrm{ppb}$ (mean \pm S.D.), $39.0 \pm 16.9$ $\mu \mathrm{g} / \mathrm{m}^{3}$, and $8.0 \pm 3.7 \mu \mathrm{g} / \mathrm{m}^{3}$, respectively. As the representative changes, the lowest daily mean value of each pollutant was shown on November 3 and 7 for the 11 days (Fig. 3), indicating that each reached a maximum both on November 5 and November 10 .

\section{Individual Measures for eNO}

Mean eNO values for the 11 days for healthy 


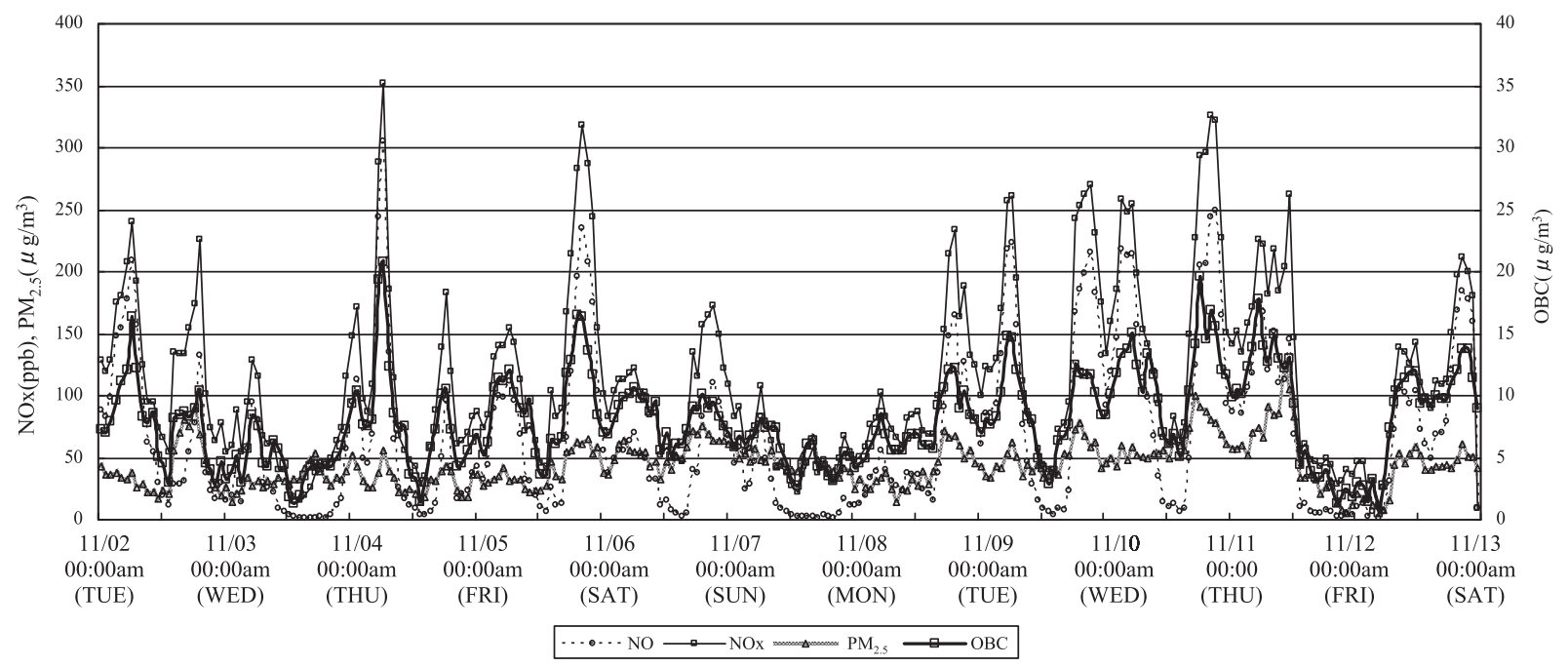

Fig. 2 Daily changes in each pollutant per hour

Mean values per hour of each pollutant, including NO, NOx, PM2.5, and OBC, for 11 consecutive days are shown. The peak value of each pollutant was observed when the traffic increased to its maximum in the mornings $(6 \sim 9$ a.m.) and evenings (6 $\sim 9$ p.m.). Daily changing averages of NO (open circle with broken line), the average of NOx (open square with thin solid line), the averages of $\mathrm{PM}_{2.5}$ (open triangle with thick solid line), and averages of $\mathrm{OBC}$ (open large square with thick solid line) are shown.

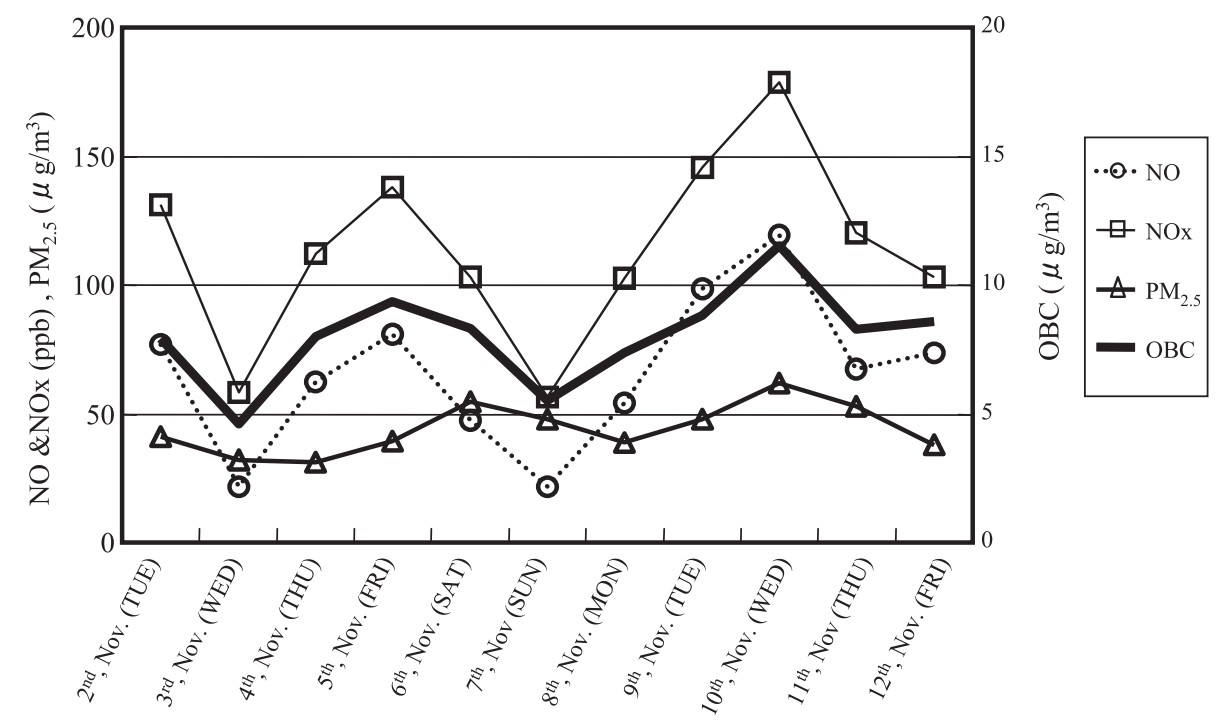

Fig. 3 Daily change in the mean values of air pollutants

Daily changes in the mean values of air pollutants are shown. The lowest daily mean value of each pollutant was shown on November 3 and 7 for the 11 days, indicating that each reached a maximum both on November 5 and November 10. The daily changing averages of NO (open circle with broken line), NOx (open square with thin solid line), $\mathrm{PM}_{2.5}$ (open triangle with thick solid line), and $\mathrm{OBC}$ (open triangle with thick solid line) are shown.

subjects $(n=16)$ and subjects with asthma $(n=3)$ were $27.1 \pm 9.7 \mathrm{ppb}$ and $57.7 \pm 18.6 \mathrm{ppb}$, respectively $(\mathrm{p}=$ 0.098). However, there was no significant correlation between eNO values and individual $\mathrm{NO}$ or $\mathrm{NOx}$ values obtained by the samplers for 24 hours. Since there was no significant correlation between the
eNO concentration and a 24-hour exposure to pollutants, we examined the relationship between eNO and the pattern of the average concentration of air pollutants before eNO measurement.

Changing patterns of the correlation coefficient for eNO on interquartile changes in $\mathrm{NO}, \mathrm{PM}_{2.5}, \mathrm{NOx}$, and 

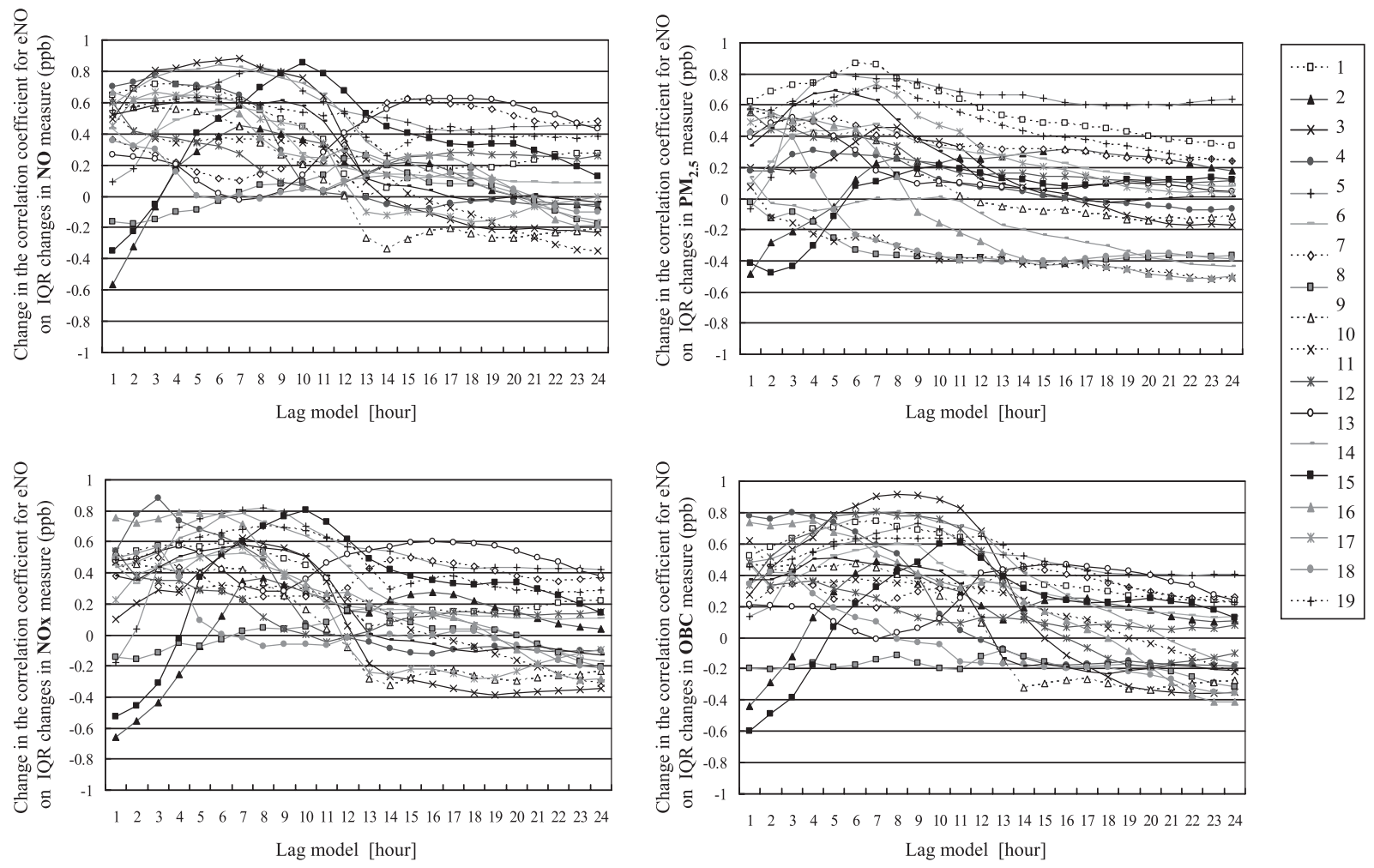

Fig. 4 Change in the correlation coefficient for eNO on interquartile changes in $\mathrm{NO}, \mathrm{PM}_{2.5}, \mathrm{NOx}$, and $\mathrm{OBC}$ for the individual hourly moving average

Each hourly moving average showed consistent associations between NO, PM2.5, NOx, OBC, and eNO for exposures during the previous 24 hours. eNO was high when concentrations of air pollutants, including NO, $\mathrm{NOx}, \mathrm{PM}_{2.5}$, and $\mathrm{OBC}$, were high.

OBC every hour for 24 hours are shown in Figure 4. Individual hourly lag models (Fig. 5) showed a consistent association between the eNO value and $\mathrm{NO}, \mathrm{PM}_{2.5}, \mathrm{NO}_{\mathrm{x}}$, and $\mathrm{OBC}$ for exposure during the previous 24 hours. The model indicated that when the eNO value was greater, there was a higher concentration of air pollutants, including $\mathrm{NO}, \mathrm{NO}_{\mathrm{x}}$, $\mathrm{PM}_{2.5}$, and $\mathrm{OBC}$. The change in eNO for an interquartile range change in $\mathrm{NO}$ measurement during the previous 8 hours increased to $0.117 \mathrm{ppb} /$ $\mu \mathrm{g} / \mathrm{m}^{3}$ (95\% CI: $0.070 \sim 0.0164$ ), and that with $\mathrm{PM}_{2.5}$ increased to $0.145 \mathrm{ppb} / \mu \mathrm{g} / \mathrm{m}^{3}$ (95\% CI: 0.062 0.228) when $\mathrm{NO}_{\mathrm{x}}$ measurements reached $0.105 \mathrm{ppb} / \mu \mathrm{g} / \mathrm{m}^{3}$ (95\% CI: 0.067 0.142). Similarly, OBC measurements reached $1.56 \mathrm{ppb} / \mu \mathrm{g} / \mathrm{m}^{3}$ (95\% CI: 0.95 2.18). The trend on the graphs strongly suggest that fluctuations in eNO were affected by changes in air pollutants over at least the previous 8-hour period, although the effects remained in a narrow range. This relation was observed both for the healthy subjects and subjects with asthma (data not shown).

\section{Discussion}

In the present study, we have shown that shortterm exposure to polluted air of at least 8 hours before measurement might affect eNO values.

A correlation between airway inflammation and air pollution has been reported. Giroux et al. ${ }^{14}$ have reported eNO levels in two groups of children with asthma residing in different environments (rural and urban) using the off-line method. The eNO values were significantly lower in children living in the rural area than in children living in the urban area and were comparable to those in healthy children. Amsterdam et al. $^{21}$ have tested the hypothesis that eNO values are affected by air pollutants in healthy nonsmoking adults using off-line and on-line methods. They have reported that the eNO values increase as pollution worsens. In a long-term study 

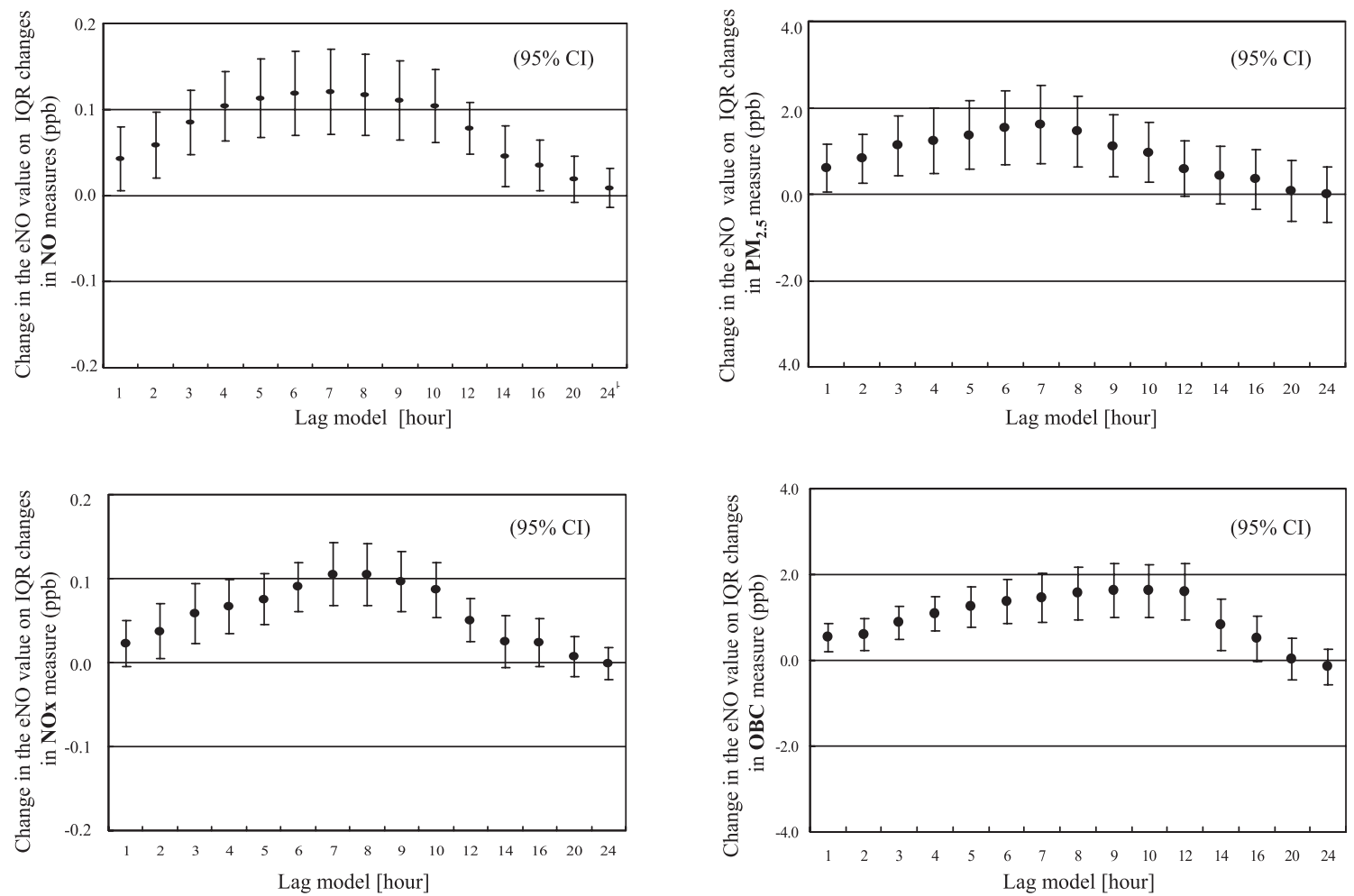

Fig. 5 Association of the eNO value with $\mathrm{NO}, \mathrm{PM}_{2.5}, \mathrm{NOx}$, and $\mathrm{OBC}$ at different lags between exposure and effect

Changes in eNO values (ppb) on interquartile changes in NO, PM2.5, NOx, and $\mathrm{OBC}$ for individual hourly lag models. Error bars indicate 95\% confidence intervals. The data of 6-, 7-, and 8-hour moving averages were created to reflect the most relevant window of exposure.

of children $^{22}$, a positive correlation between eNO values and the level of air pollutants, including $\mathrm{NO}_{2}$, $\mathrm{CO}, \mathrm{PM}_{2.5}$, and pollen, was observed. Franklin et al. ${ }^{6}$ found in their long-term study (5 to 100 weeks) with the off-line method that prolonged exposure to air pollution affects eNO values in children. All these previous studies suggest that eNO values are affected by changes in pollutant levels in ambient air. However, ambient conditions are can each day, each hour, or even each moment owing to traffic congestion. As shown in Figure 3, air pollution reached a maximum on both November 5 and November 10, suggesting that it likely to be affected by the Japanese business system, in which defrayment by banks is made on the $5^{\text {th }}$ and $10^{\text {th }}$ of each month. Also, the mean values of air pollutants reached a maximum on weekdays and dropped on the weekend (November 7) and on a national holiday (November 3) owing to a reduced traffic volume. This finding also suggests pollution reached a maximum during business hours only, until 3 p.m., when banks generally close in Japan. Epidemiological studies regarding air pollution should always consider local factors such as those described above. Thus, we need to clarify the shortterm effects of air pollution as well as long-term effects, as previously performed ${ }^{6}$. When polluted air may affect the eNO concentration significantly, we should take account of this when using eNO values in epidemiological studies to detect the effects of airway inflammation, such as in bronchial asthma.

In the present study, we have shown that eNO values were easily affected by various concentrations of pollutants in ambient air. The peak values of each pollutant, including $\mathrm{NO}_{2}, \mathrm{CO}, \mathrm{PM}_{2.5}$, and $\mathrm{OBC}$, were similarly observed when traffic increased to its maximal volume in the mornings and evenings. The present data clearly show that short-term exposure to air pollutants for at least 6 to 8 hours before eNO measurements affected the results (Fig. 4).

However, the present study has several 
limitations. First, only school children were studied. Steerenberg et $\mathrm{al}^{23}$ report that the daily eNO value is positively associated with ambient $\mathrm{CO}$ and NO in healthy nonsmoking adults; exposure in the morning to a high level of outdoor pollution is associated with an increased eNO level which persists for up to 5 hours. However, the data from eight adult subjects in our preliminary study contrasted with their findings (data not shown). Concerning the behavior of children, the areas they go to are likely to be limited after school, whereas adult subjects might move over a wider area for their work. Second, no current smokers were included in the present study. It has been reported that the eNO value is strongly affected by smoking status ${ }^{24}$, although the effects of passive smoking could not be avoided.

In conclusion, short-term exposure to polluted air of at least 8 hours before measurement might affect eNO values. Therefore, caution should be exercised when measuring eNO values in epidemiological studies.

This study was performed as a part of contract research for the Ministry of the Environment, Japan.

\section{References}

1. Kharitonov SA, Yates D, Robbins RA, Logan-Sinclair $\mathrm{R}$, Shinebourne EA, Barnes PJ: Increased nitric oxide in exhaled air of asthmatic patients. Lancet 1994; 343 : 133-125.

2. Lundberg JO, Nordvall SL, Weitzberg E, Kollberg H, Alving K: Exhaled nitric oxide in pediatric asthma and cystic fibrosis. Arch Dis Child 1996; 75: 323-326.

3. Byrnes CA, Dinarevic S, Shinebourne EA, Barnes PJ, Bush A: Exhaled nitric oxide measurements in normal and asthmatic children. Pediatr Pulmonol 1997; 24: 312-331.

4. Steerenberg PA, Snelder JB, Fishcer PH, Vos JG, van Loveren $\mathrm{H}$, van Amsterdam JG: Increased exhaled nitric oxide on days with high outdoor air pollution is of endogenous origin. Eur Respir J 1999; 13: 334-337.

5. Steerenberg PA, Nierkens S, Fischer PH, et al. Traffic-related air pollution affects peak expiratory flow, exhaled nitric oxide, and inflammatory nasal markers. Arch Environ Health 2001; 56: 167-174.

6. Franklin PJ, Turner AW, Mutch RC, Stick SM: Measuring exhaled nitric oxide in infants during tidal breathing: methodological issues. Pediatr Pulmonol 2004; 37: 24-30.

7. Shima M, Adachi M: Indoor nitrogen dioxide in homes along trunk roads with heavy traffic. Occup Environ Med 1998; 55: 428-433.

8. Wjst M, Reitmeir P, Dold S, et al:: Road traffic and adverse effects on respiratory health in children. BMJ 1993; 307: 596-600.
9. Nitta H, Sato T, Nakai S, Maeda K, Aoki S, Ono M: Respiratory health associated with exposure to automobile exhaust. I. Results of cross-sectional studies in 1979, 1982, and 1983. Arch Environ Health 1993; 48: 53-58.

10. Hoek G, Brunekreef B, Goldbohm S, Fischer P, van den, Brandt PA: Association between mortality and indicators of traffic-related air pollution in the Netherlands: a cohort study. Lancet 2002; 360: 12031209.

11. Zmirou D, Gauvin S, Pin I, et al.: Traffic related air pollution and incidence of childhood asthma: results of the Vesta case-control study. J Epidemiol Community Health 2004; 58: 18-23.

12. Ferris BG: Emidemiology Standardization Project. Recommended respiratoy disease questionnaires for use with adults and children epidemiological research. Am Rev Respir Dis 1978; 118: 7-53.

13. Saito J, Inoue $K$, Sugawara A, Yoshikawa $M$, Watanabe $\mathrm{K}$, et al.: Exhaled nitric oxide as a marker of airway inflammation for an epidemiologic study in schoolchildren. J Allergy Clin Immunol 2004; 114: 512-516.

14. Giroux M, Bremont F, Ferrieres J, Dumas JC: Exhaled NO in asthmatic children in unpolluted and urban environments. Environ Int 2001; 27: 335-340.

15. Koenig JQ, Jansen K, Mar TF, et al:: Measurement of offline exhaled nitric oxide in a study of community exposure to air pollution. Environ Health Perspect 2003; 111: 1625-1629.

16. Fischer PH, Steerenberg PA, Snelder JD, van Loveren $\mathrm{H}$, van Amsterdam JG: Association between exhaled nitric oxide, ambient air pollution and respiratory health in school children. Int Arch Occup Environ Health 2002; 75: 348-353.

17. Munakata M, Saito J, Hasunuma H, Ishimaru Y, Kanegae H, Kudoh S: Development of new method for off-line measurement of exhaled NO (FENO) compatible to on-line method. Eur Respir J 2004; 24: Suppl. 48, 267s.

18. The report on the investigative method to investigate how a small area of air poluution influence on residents' health, Published by Ministory of the Enviroment, Japan, 1993.3.

19. Watanabe M, Takamatsu T, Koshikawa MK, Sakamoto K, Inubushi K: Simultaneous determination of atmospheric sulfur and nitrogen oxides using a battery-operated portable filter pack sampler. J Environ Monit 2006; 8: 167-173.

20. Admkiewicz G, Ebelts S, Syring M, et al.: Association between air pollution exposure and exhaled nitric oxide in an elderly population. Thorax 2004; 59: 204209.

21. Van Amsterdam JG, Verlaan AP, van Loveren $H$, Vos SG, Opperhuizen A, Steerenberg PA: The balloon technique: a conventional method to measure exhaled NO in epidemiological studies. Int Arch Occup Environ Health 1999; 72: 404-407.

22. Steerenberg PA, Bishoff EW, de Klerk A, et al: Acute effect of air pollution on respiratory complaints, exhaled NO and biomarkers in nasal lavages of allergic children during the pollen season. Int Arch Allergy Immunol 2003; 131: 127-137.

23. Van Amsterdam JG, Verlaan BP, van Loveren $H$, Opperhuizen A, Steerenberg PA: Air pollution is associated with increased level of exhaled nitric oxide in nonsmoking healthy subjects. Arch Environ Health 1999; 54: 331-335.

24. Franklin PJ, Turner S, Mutch R, Stick SM: Parental smoking increases exhaled nitric oxide in young children. Eur Respir J 2006; 28: 730-733.

(Received, October 4, 2006) (Accepted, December 4, 2006) 